\title{
Vacuum Insulation Panels - An Assessment of the Impact of Accelerated Ageing on Service Life
}

\author{
Roman Kunič \\ University of Ljubljana, Faculty of Civil and Geodetic Engineering, Slovenia
}

Vacuum insulation panels (VIP) are the most effective thermal insulation and are primarily used where not much space is available and extremely high thermal insulation properties are required. Panels are already widely used in industry (insulation of the front doors and side walls of refrigerators and freezers for domestic appliances), for logistic purposes (transport containers, storage tanks, campers, refrigeration and other vehicles), for the insulation of laboratory and professional devices and insulation of various construction elements, such as elements for doors, furniture.

Since the entry of atmospheric air gases into VIP panels represents the most harmful influence on their excellent thermal insulation properties, our research was focused on the analysis of accelerated ageing and determination of service life caused by this influence. The primary objective of the research was to define the theoretical base supporting measurements of accelerated testing and the connection between ageing and the service life of VIP panels. Arrhenius law of accelerated testing was used as a theoretical support to experimental testing of VIP panels at high temperatures and different exposure times. These results are useful in order to control quality, resistance to ageing and determining the life expectancy of VIP panel products, the characteristics of which can be determined in a significantly shorter time during accelerated testing than during real service life conditions.

The accelerated ageing laboratory test measurements and simulation analysis confirm that VIP panels are a durable and high quality product.

Keywords: service life, ageing, accelerated testing, Arrhenius law, activation energy, vacuum insulation panel (VIP)

\section{O INTRODUCTION}

Most envelope constructions applied due to new demands for energy savings, greatly increase the thickness of thermal insulation, whereby a thickness of 30 or even 50 centimetres is not unusual. Extremely high energy efficient buildings, such as Near-0-Energy $(\mathrm{N}-0-\mathrm{E})$ houses, require thermal insulation with a $\mathrm{U}$-value even lower than $0.10 \mathrm{~W} /\left(\mathrm{m}^{2} \cdot \mathrm{K}\right)$, which has resulted in layers of conventional thermal insulation of at least $30 \mathrm{~cm}$. This imposes not only technical constraints but also has negative aesthetic effects. The same situation is also encountered in the industry of refrigerators and other domestic and professional appliances, transport containers and vehicles, campers and laboratory equipment, where there is a space limitation.

It should be noted that the optimal thickness of the heat insulating layer is always obtained at the expense of the efficiency of the available volume, since the net yield of the useful volume of the envelope is often much smaller. On the other hand, it is also true that designers want to gain space.

Vacuum insulation panels are substantially more efficient (up to ten times) than conventional insulating materials [1]. The thermal conductivity may be lower than $0.0030 \mathrm{~W} /(\mathrm{m} \cdot \mathrm{K})$ and the thermal resistance of a panel only $20 \mathrm{~mm}$ thick can even reach $6.66\left(\mathrm{~m}^{2} \cdot \mathrm{K}\right) / \mathrm{W}$. This means that high heat resistance with an extremely small thickness of insulation panels can be achieved with the help of VIP. The thermal insulation envelope shrinks, becoming up to five times thinner.

Growing interest has been noted recently in replacing standard insulation with the VIP type, leading to new issues that need to be addressed and clarified. One of the most important aspects of VIP is assessment of their service life and their reliability during their life cycle. This has a direct impact on reducing the consumption of raw materials and environmental protection aspects, such as recycling, planning and management of waste resulting from its removal. Accelerated ageing and determination of the life expectancy of thermal insulation materials play an important part in this.

The experimental methods that were used in this work aimed at evaluating the rate of degradation of VIP panels, i.e., to determining the values of thermal conductivity as a function of thermal loads. By taking into account Arrhenius law of accelerated ageing [2], the ageing mechanism of vacuum insulation panels was determined. Other loads, such as humidity and thermal cycling can be used and their effect on the service life of VIP can be assessed. However, we believe that temperature loads have the primary impact on VIP failure and thus deserve a detailed investigation.

\section{VIP PANELS THEORY}

VIP panels are extremely suitable for cases in which a large thickness of insulating layers represents a 
physical barrier, where using VIP panels achieves high thermal insulation without significantly increasing the thickness of the complete insulation layer.

The panels are already used for insulation in various construction elements, such as elements for doors, furniture), logistics (transport and packaging containers, special containers and storage tanks, refrigeration vehicles), insulation of domestic appliances (refrigerator doors, sides of refrigerators and freezers) and for insulation of various laboratory and professional appliances and devices. The Slovenian manufacturer of domestic appliances thus already uses VIP panels in selected models of refrigerators and freezers for more demanding customers.

A VIP panel - non-homogenous composite thermal insulation material - is made from different components: first, a special film, which is vacuum tight and enables the insulating core to be sealed against air and moisture diffusion: second, vacuumated thermal insulation without air or moisture and, third, special gas and/or moisture absorbers, which are usually inserted inside the VIP panel based on special needs.

Panels can be manufactured in any size. In contrast to other insulation materials, after their manufacture, VIP cannot be cut to specific dimensions or disintegrated, and no piercing or mechanical fasteners are allowed.

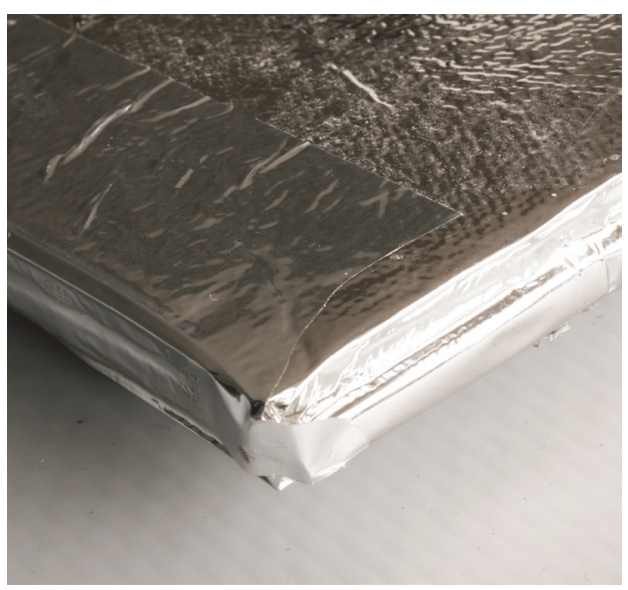

Fig. 1. Vacuum insulation panel

The most important issue is to prevent air from entering from outside, which can happen due to mechanical damage or an imperfect weld bonding the two halves of the outer foils. It should be born in mind that even a small amount of air entering a VIP has an enormous effect on increasing its thermal conductivity.

\subsection{Thermal Insulated Core Material}

Thermal insulation of the core at normal atmospheric pressure is also important because after the VIP panel service time is reached or the vacuum is lost due to puncturing, deformation of the outer foils or damage during transport, the residual thermal insulation still provides a certain insulation effect. In the study, we used core material made of specially processed glass fibres, without any binders, with a thermal conductivity value of about $32 \mathrm{~mW} /(\mathrm{m} \cdot \mathrm{K})$, as well as more efficient core materials such as micro-porous based silica powder structures. Unfortunately, the latter are considerably more expensive (such materials have a thermal conductivity of about $22 \mathrm{~mW} /(\mathrm{m} \cdot \mathrm{K})$. Core material densities are usually in the range of 170 to $210 \mathrm{~kg} / \mathrm{m}^{3}$.

The core material must have an open cell structure. It can be in powder form or have a fibrous structure, both allowing the air to be pumped out almost completely, thus enabling the creation of near vacuum conditions, estimated to be up to $1 / 1000$ 's of atmospheric pressure $(1 \mathrm{mbar})$ or even $100 \times$ smaller (i.e., just $1 \mathrm{~Pa}$ ). The core material must be compact enough to withstand high compression stresses caused by the air pressure without any additional load on the panel (represents a pressure of 1 bar).

\subsection{Multilayer Envelope Foil as a Protection Film}

Special multilayer films (foils) should ensure air tightness against all atmospheric gases and a total vapour barrier for preventing the diffusion of moisture and air. One of the most crucial properties of VIP is foil resistance to ageing, which is related to its chemical composition and overall quality, and its ability to be bonded. The film structure is multi-layer (aluminium foil, PT, PET, HDPE, PP, nylon, etc.), while bonding is achieved by using appropriate adhesives. High quality foils have recently entered the market and better bonding systems have been developed [3].

\subsection{Gas and Moisture Absorbers}

In order to reduce the influence of penetration of moisture and gases, special absorbers can be added to panels during production. They absorb gases, moisture or a combination of both. In our basic study, we focused mainly on the impact of accelerated ageing without additional absorbers, and a core made of silica powder is already a good moisture absorber. 


\subsection{Basic Instructions for Using Vacuum Insulation}

VIP panels should be well protected during transport, storage and handling and any mechanical damage must be avoided. Practice shows that most damage occurs before and during the installation of panels. Sharp objects or surfaces should not be in contact with VIP panels.

A larger panel performs better because the initial thermal conductivity is lower and resistance to ageing is better. In other words, thermal conduction through the edges of a panel is quite low compared to thermal conduction through the whole surface of a VIP panel. At the same time, a relatively shorter length of edges compared to the whole panel area, means the vacuum inside VIP panels is better maintained.

An additional vapour barrier is usually needed in cases in which VIP panels are used on the inner or warmer and usually higher vapour pressure side of the thermal barrier.

\section{METHODOLOGY}

\subsection{History of Accelerated Ageing}

Historically, accelerated ageing has been used in very rapid testing under simulated field conditions in the laboratory. In many cases, this leads to excessive failures of such materials or products, which would not have occurred under normal conditions of use during normal service life. The conditions of accelerated ageing of various materials or products must therefore be adjusted to the conditions of normal use as far as possible. Some references to the results of relevant successful studies, tests and analysis are shown in Table 1; bituminous products with different additives which are used to extend service life [4], analysis of electrical cable insulation against ageing [5] and [6], ageing studies of different Thickness Insensitive Spectrally Sensitive (TISS) coatings for solar collectors [7] and [8].

\subsection{Activation Energy}

The threshold for the reaction is the minimum energy - activation energy - that leads to a reaction. In chemistry and biology, it is the threshold energy, or the energy required to produce a chemical reaction. In other words, this is the minimum energy required for the initiation of certain chemical changes and it describes the material's characteristics and allows indirect prediction of its degradation or ageing under the influence of various external factors. In order to
Table 1. Values of activation energy for some materials

\begin{tabular}{|c|c|c|}
\hline \multirow[t]{2}{*}{ Material } & \multicolumn{2}{|c|}{$\begin{array}{l}\text { Activation energy } \\
E_{a}[\mathrm{~kJ} / \mathrm{mol}]\end{array}$} \\
\hline & from & to \\
\hline Polyvinylchloride - PVC [9] & 24.5 & 37.5 \\
\hline Cement, contaminated with soil [10] & 25.0 & 58.0 \\
\hline Soil [11] & 25.0 & 71.0 \\
\hline Polycarbonate - UV stabilized [12] & 26.0 & 28.5 \\
\hline Batteries - empty (used) [13] & 31.0 & 34.0 \\
\hline Polypropylene [14] & 35.0 & 50.0 \\
\hline Natural oil sand bitumen [15] & 36.9 & 46.7 \\
\hline Rubber, vulcanized with sulphur [9] & 37.0 & 40.0 \\
\hline $\begin{array}{l}\text { Rubber, vulcanized with sulphur and radiation } \\
\text { [12] }\end{array}$ & 45.0 & 49.0 \\
\hline Plastic tiles for cars - durable [16] & 48.0 & 69.0 \\
\hline Batteries - new (not used) [13] & 50.0 & 55.0 \\
\hline Bitumen [17] & 53.9 & 57.9 \\
\hline Concrete [11] & 55.0 & 70.0 \\
\hline Bituminous membrane - oxidized bitumen [4] & 58.4 & 58.4 \\
\hline Elastomeric butyl [14] & 60.0 & 100.0 \\
\hline Polyurethane [14] & 65.0 & 119.0 \\
\hline Cement [18] & 71.0 & 73.0 \\
\hline $\begin{array}{l}\text { Bituminous membrane - APP modified } \\
\text { bitumen [4] }\end{array}$ & 75.7 & 75.7 \\
\hline EPDM [14] & 78.0 & 127.0 \\
\hline $\begin{array}{l}\text { Epoxy resin reinforcement with glass fibbers } \\
\text { [19] }\end{array}$ & 80.0 & 135.0 \\
\hline Polychloroprene rubber [20] & 82.0 & 96.0 \\
\hline Neoprene rubber [14] & 84.0 & 88.0 \\
\hline $\begin{array}{l}\text { Bituminous membrane - SBS modified } \\
\text { bitumen [4] }\end{array}$ & 85.2 & 85.2 \\
\hline Polyethylene for cable insulation [5] & 88.0 & 107.0 \\
\hline $\begin{array}{l}\text { TISS - Thickness Insensitive Spectrally } \\
\text { Sensitive coating, Polyurethane substrate, type } \\
\text { B [7] }\end{array}$ & 96.0 & 96.0 \\
\hline Polyvinylchloride - PVC for cable insulation [6] & 98.0 & 99.0 \\
\hline Casts made of Al alloy [9] & 135.0 & 145.0 \\
\hline EP rubber [21] & 160.0 & 160.0 \\
\hline $\begin{array}{l}\text { TISS - Thickness Insensitive Spectrally } \\
\text { Sensitive coating, Polyurethane substrate, type } \\
\text { A [7], [8] }\end{array}$ & 160.0 & 166.2 \\
\hline Ethylene Vinyl Acetate (EVA) [22] & 176.0 & 184.0 \\
\hline Alpha Olyphine Co-Polymer [21] & 180.0 & 180.0 \\
\hline EP Graphite Co-Polymer [21] & 200.0 & 200.0 \\
\hline Atactic Polypropylene - APP [21] & 600.0 & 600.0 \\
\hline Isotactic Polypropylene - IPP [21] & $1,300.0$ & $1,300.0$ \\
\hline
\end{tabular}

exceed the reaction level of the activation energy, we need to achieve a sufficiently high temperature and correct orientation and energy of molecules.

Activation energy is usually expressed as the energy $[\mathrm{J}]$ required for the reaction of one mole of a substance or reactant, i.e., J/mol. For substances with high activation energy (more than $170 \mathrm{~kJ} / \mathrm{mol}$ ), 
reactions are only detectable at temperatures higher than $400{ }^{\circ} \mathrm{C}$.

Table 1 shows the activation energy for various materials. If cement ( $E_{a}$ is from 71 to $73 \mathrm{~kJ} / \mathrm{mol}$ ) is contaminated with soil, the activation energy is only one-third to one-quarter of the original value (from 24.5 to $37.5 \mathrm{~kJ} / \mathrm{mol}$ ). Polymers that are used for mixing with other materials in order to improve resistance to low and high temperatures and the UV spectrum of solar radiation, i.e., to increase the resistance to ageing of the majority of products, have extremely high levels of activation energies; atactic polypropylene (APP) has an activation energy of 600 $\mathrm{kJ} / \mathrm{mol}$ and isotactic polypropylene (IPP) of 1300 $\mathrm{kJ} / \mathrm{mol}$.

\subsection{The Arrhenius Equation}

The Arrhenius equation describes the dependence of the speed of chemical reactions on various physical parameters, such as temperature, humidity, pressure etc. The magnitude of changes affects the ability of the material to resist those factors that provide activation energy. The first steps of the theory were proposed by the Dutch chemist, J. H. van't Hoff, in 1884. Five years later, the Swedish chemist and later Nobel Prize winner, Svante Arrhenius published a physical interpretation of the equation. Arrhenius claimed that, in order to achieve a reaction that changes the material, a sufficient amount of energy needs to be supplied.

The Arrhenius equation describes the logarithmic relationship (based on a natural logarithm) between temperature and activation energy. Despite the fact that the defaults simplify many effects as being temperature independent, several studies have clearly confirmed that the process of degradation of a material can be sufficiently accurately described by a simple Arrhenius equation [2].

In thermal balance at absolute temperature $(T)$, the parts of molecules that have a kinetic energy of more than $\left(E_{a}\right)$ can be calculated by MaxwellBoltzmann's distribution of statistical mechanics and are in accordance with the literature [2] in relation to:

$$
k=A \cdot \mathrm{e}^{-\frac{E_{a}}{R \cdot T}},
$$

where $E_{a}$ is activation energy $[\mathrm{J} / \mathrm{mol}], R$ ideal gas constant, $T$ temperature $[\mathrm{K}], k$ specific rate of reaction, reaction constant factor or reaction speed [1/s] , and $A$ pre-exponent factor or frequency factor of a certain reaction $[1 / \mathrm{s}]$. By using the natural logarithm, the Arrhenius equation can be expressed as:

$$
\ln k=-\frac{E_{a}}{R} \cdot \frac{1}{T}+\ln A,
$$

If the specific rates of reactions $\left(k_{1}\right.$ and $\left.k_{2}\right)$ at two different temperatures $\left(T_{1}\right.$ and $\left.T_{2}\right)$ are known, the activation energy can be determined [16]:

$$
\ln \frac{k_{2}}{k_{1}}=\ln a_{T}=\frac{E_{a}}{R} \cdot \frac{T_{2}-T_{1}}{T_{1} \cdot T_{2}},
$$

where $\alpha_{T}$ is coefficient of acceleration of ageing due to degradation at elevated temperatures [-].

In accordance with Arrhenius law (Eq. 3), in order to determine the activation energy $\left(E_{a}\right)$, at least two accelerated ageing testing procedures at two different temperatures are needed. Changes of temperature from $T_{1}$ to $T_{2}$ lead to an acceleration of ageing $\left(a_{T}\right)$, which depends on the value of activation energy $E_{a}$ (Eq. 3). In other words, if after a time period $t_{1}$ at a temperature level $T_{1}$ the same degradation is caused as after a time period $t_{2}$ at temperature level $T_{2}$, then the acceleration of degradation processes caused by changes in temperature can also be discovered. This feature is called the activation energy $\left(E_{a}\right)$.

Since the relationship between the temperature and the reaction is constant and follows Arrhenius law, then the graph representing $\ln k$ as a function of $1 / T$ is a straight line (Fig. 2). The slope of the graph is in interdependence with the activation energy $E_{a}$, more precisely with $-E_{a} / R$. The higher the activation energy, the greater the slope of the curve.

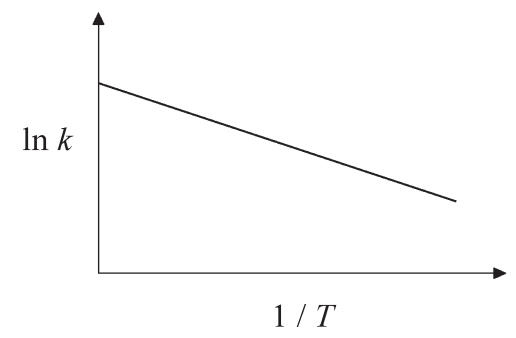

Fig. 2. According to Arrhenius law, the graph represents the relation between $\ln \mathrm{k}$ and $1 / T$

Arrhenius equation thus provides a qualitative basis for the relation between activation energy and the rate at which a certain reaction takes place. This process is the basis for experimental chemical kinetics, which is used for the determination of activation energy for individual reactions.

In the present analysis, Arrhenius equation (Eq. 3) was used as a suitable empirical expression to describe temperature dependence of VIP panels' degradation process. 


\subsection{Simulation Analyses}

The main advantages of simulation analyses in comparison with testing in a real, natural environment are rapid implementation and rapid acquisition of results and thus lower prices of testing procedures [12]. The procedure of accelerated ageing in which the level of a particular load or several different loads is increased above the load level in normal use, is an alternative to observation under natural conditions of use. Testing time should thus be significantly shorter [12].

Service life does not usually mean a period without any deterioration. It is also a function of the manner of use and maintenance. Flaws and damage are a matter of subjective assessment but are used as the basis for determining the life expectancy of a particular material, product or component in the system. Properties often have more than two states (airproof against air penetration, waterproof against water leakage, resistance to instability, etc.) but the determination of slow degradation due to a continuous ageing process is much more difficult. In the case of a dramatic or even catastrophic drop in quality (also called 'sudden death'), the determination of service life is very simple. More often, degradation is a slow, continuous reduction of quality and usefulness and other characteristics of the product. In such a case, we need to determine the maximum or acceptable change in the product quality and its properties, i.e., we need to define the maximum allowable degradation of a product that is still acceptable to users, as well as the appearance, functionality and all other relevant parameters of products at the end of their service life [23].

\section{EXPERIMENTAL}

Laboratory measurements and numerical analyses were carried out on VIP panels exposed to stress under high temperature in an oven (Fig. 3).

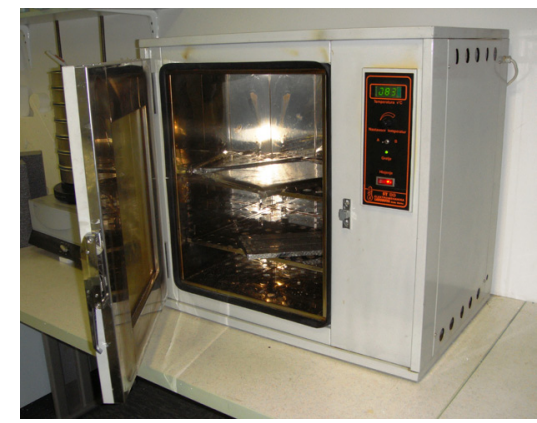

Fig. 3. Oven for accelerated ageing temperature stress
Since most films are unstable or could be permanently damaged above temperatures around 105 to $110{ }^{\circ} \mathrm{C}$, we selected the following accelerated ageing temperatures: $100,90,80,70$ and $60^{\circ} \mathrm{C}$, with time exposures from half a day up to 3 months or, in some cases, even longer.

Accelerated ageing test was performed on VIP panels with dimensions approx. $25 \times 25 \mathrm{~cm}$ (total of 112 samples).

\subsection{Thermal Conductivity}

We can assume that the primary function and the most important requirement for VIP panels is excellent thermal conductivity, which also depends on the quality of application, installation, details, thermal bridges, design connections of constructional complexes and base surfaces. The thermal conductivity measurements were taken with a thermal conductivity meter (Fig. 4). The goal is to maintain thermal conductivity as low as possible. Thermal conductivity measurements at the UAE Institute in Bavaria have confirmed values even lower than $3 \mathrm{~mW} /(\mathrm{m} \cdot \mathrm{K})$.

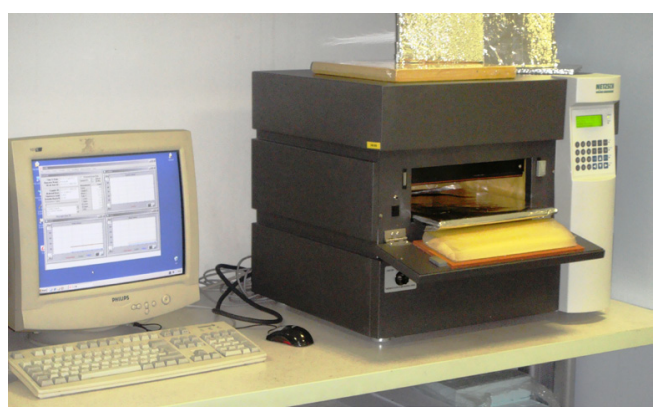

Fig. 4. Laboratory measurement of thermal conductivity

Because of high hygroscopic properties of the tested micro-porous-based silica powder core material in VIP panels, the further aspect of accelerated tests focused on thermal loads and not the influence of humidity. Thus, the assumption with only temperature dependence of the degradation process was accepted for indoor environment or refrigerator use of VIP panels. However, if the same insulation was used in high humidity and at elevated or high temperatures (up to around $100{ }^{\circ} \mathrm{C}$ ), both, thermal and humidity dependence of VIP panels' degradation process should be taken into account.

\subsection{Definition of Service Life of VIP Panels, Mechanism of Degradation and Its Functional Capability}

The main problems encountered in applying the recommended accelerated test procedure for VIP 
panels are, firstly, the selection and application of suitable thermal loads and secondly, to observe degradation over different periods of time. Due to the non-reversible deformation of VIP panels, overexposure to excessively high thermal loads must be avoided during the procedure of accelerated ageing, since they could cause thermal instability and disintegration of the material (mainly of multilayer protection foils).

It is difficult to determine the deterioration of the product or the whole system in percentage terms. The thermal conductivity value of VIP panels with higher than double value of initial thermal conductivity, thus worse insulation property, do not perform their important function of resistance to ageing well. We set the assumption of service life as the time at which the value of thermal conduction doubled.

In order to predict the service life according to Arrhenius law, it is necessary to know the activation energy $\left(E_{a}\right)$, i.e., the threshold energy required to produce a chemical reaction. In general, the activation energy can be determined from the measured changes of any of the material's properties that can serve as a degradation indicator. In order to obtain the activation energy connected to studying the degradation process of VIP panels, we used the determination of thermal conductivity value.

In addition to mechanical damage or puncture, the entry of gases (i.e., air or other atmospheric gases) or moisture (primarily through diffusion) significantly reduces thermal insulation. Even small amounts of gases or moisture cause a large increase in thermal conductivity [24].

The assumption for service life span in this study was the time at which double of the initial thermal conductivity of VIP panel is reached (i.e. increase of thermal conductivity by $100 \%$ ).

\section{RESULTS AND DISCUSSION}

The most important loads on a VIP panel, if mechanical damage is excluded, are elevated temperature and humidity. These two loads individually or simultaneously and at higher intensity, lead to an increase in the passage of gases and moisture into a VIP panel. This process significantly increases the thermal conductivity, which is limited by the value of the thermal insulation of the core material. Our task was to establish the time at which double the initial thermal conductivity is reached.

During service life period over years or decades, gases and moisture slowly and constantly penetrate into VIP panels, primarily through sealants of multilayer foils, thus increasing vapour pressure, resulting in higher thermal conductivity. The measurements and analysis in this study were focused on thermal load of VIP panels during accelerating ageing tests. It is possible to neglect the effects of moisture dependence because of high hygroscopic properties of VIP core material (micro-porous silica powder) and because of relative low ambient temperature during the entire service life (indoor or domestic appliance refrigerator use). In addition, temperature and humidity have possible influence on service life only when mechanical deformation of VIP panels occurs, and not if they are used properly; without any deleterious chemical, physical or mechanical influence.

\subsection{Assessment of Accelerated Ageing}

Degradation at elevated temperature is determined as follows [12]:

$$
\begin{gathered}
a_{T}=\frac{k_{2}}{k_{1}}=\frac{\tau_{2}}{\tau_{1}}=e^{\frac{E_{a}}{R}\left(\frac{1}{T_{1}}-\frac{1}{T_{2}}\right)} \Rightarrow E_{a}=\frac{R \cdot \ln a_{T}}{\left(\frac{1}{T_{1}}-\frac{1}{T_{2}}\right)}, \\
a_{T}=\frac{k_{2}}{k_{1}}=\frac{\tau_{1}}{\tau_{2}}=e^{-\frac{E_{a}}{R}\left(\frac{1}{T_{2}}-\frac{1}{T_{1}}\right)}=e^{\frac{E_{a}}{R}\left(\frac{1}{T_{2}}-\frac{1}{T_{1}}\right)}=e^{\frac{E_{a}}{R}\left(\frac{T_{2}-T_{1}}{T_{1} \cdot T_{2}}\right)},
\end{gathered}
$$

where $k_{1}$ is specific reaction rate under accelerated test conditions $[1 / \mathrm{s}], k_{2}$ specific reaction rate under normal or working conditions $[1 / \mathrm{s}], \tau_{1}$ time to degradation during accelerated ageing test temperature [hour, day, week, month, year], $\tau_{2}$ time to degradation at operating temperature, therefore during normal use [month, year, decade], $T_{1}$ testing temperature $[\mathrm{K}]$, and $T_{2}$ operating or working temperature $[\mathrm{K}]$.

We assume that the limit of functionality of a VIP panel (i.e., complete degradation) occurs when it reaches the thermal conductivity of the core under normal atmospheric pressure, which in our case is $32 \mathrm{~mW} /(\mathrm{m} \cdot \mathrm{K})$ for glass fibres and $22 \mathrm{~mW} /$ $(\mathrm{m} \cdot \mathrm{K})$ for silica powder. In accordance with Eq. (4), the procedure of accelerated ageing at two or more different temperatures and, as a consequence, at two or more different exposure times, enables the calculation of the activation energy. The proposed temperatures for accelerated ageing testing procedures (from 60 to $100{ }^{\circ} \mathrm{C}$ ) were confirmed as the confidence interval by means of the results of partly degraded samples. Above such temperatures, too high or even totally degraded samples can be expected, i.e., no reliable comparisons can be made and the results represent non-Arrhenius behaviour.

From all the obtained results, the value of the activation energy for VIP panel products $\left(E_{a}=66.35\right.$ 
$\mathrm{kJ} / \mathrm{mol}$, Table 2) can be determined. The value of activation energy is used to evaluate the behaviour of the VIP panel products exposed to different temperatures, by interpolation within the testing temperature interval at which accelerated ageing is performed or, more commonly, by extrapolation outside the testing temperature interval (Tables 3 and 4). In doing so, it is necessary to be careful and critical of the results and to be aware that extrapolation to temperatures far outside the testing interval cannot be accurate since, in such cases, the influence of the neglected temperature dependent pre-exponent factor in the Arrhenius equation becomes more important and the results are increasingly inaccurate.

Table 2. Activation energy of vacuum insulation panels

\begin{tabular}{cccccc}
\hline No. & \multicolumn{2}{c}{$\begin{array}{c}\text { Ageing at lower } \\
\text { temperatures }\end{array}$} & \multicolumn{2}{c}{$\begin{array}{c}\text { Ageing at higher } \\
\text { temperatures }\end{array}$} & $\begin{array}{c}\text { Activation } \\
\text { energy }\end{array}$ \\
\cline { 2 - 5 } & $\begin{array}{c}\text { Temp. } \\
{\left[{ }^{\circ} \mathrm{C}\right]}\end{array}$ & $\begin{array}{c}\text { Ageing } \\
{[\text { days }]}\end{array}$ & $\begin{array}{c}\text { Temp. } \\
{\left[{ }^{\circ} \mathrm{C}\right]}\end{array}$ & $\begin{array}{c}\text { Ageing } \\
{[\text { days }]}\end{array}$ & $E_{a}[\mathrm{~kJ} / \mathrm{mol}]$ \\
\hline 1 & 60 & 51 & 80 & 14 & 63.234 \\
\hline 2 & 60 & 58 & 80 & 14 & 69.525 \\
\hline 3 & 60 & 148 & 80 & 21 & 95.513 \\
\hline 4 & 60 & 178 & 80 & 51 & 61.140 \\
\hline 5 & 60 & 51 & 100 & 5 & 60.015 \\
\hline 6 & 60 & 58 & 100 & 6 & 58.627 \\
\hline 7 & 60 & 148 & 100 & 6 & 82.835 \\
\hline 8 & 60 & 178 & 100 & 14 & 65.709 \\
\hline 9 & 80 & 148 & 100 & 58 & 51.322 \\
\hline 10 & 80 & 148 & 100 & 51 & 58.368 \\
\hline 11 & 80 & 178 & 100 & 51 & 68.480 \\
\hline 12 & 80 & 178 & 100 & 58 & 61.434 \\
\hline Average value of activation energy $\left(E_{a}\right):$ & & 66.350 \\
\hline Median value of activation energy $\left(E_{a}\right):$ & & 62.334 \\
\hline Standard deviation of activation energy $\left(E_{a}\right):$ \\
\hline \multicolumn{5}{l}{}
\end{tabular}

\subsection{Determination of Service Life}

It can be concluded that the thermal load to which we exposed the VIP panels caused a degradation process that followed Arrhenius law. It is therefore possible to transform the thermal load (which represents degradation kinetics at the specific level of temperature) in any of the other thermal load curves, only in cases in which the same activation energy $\left(E_{a}\right)$ is used for all transformations [8]. In other words, the results obtained from experimentally accelerated ageing, from the activation energy obtained by Arrhenius law and, consequently, on the basis of the calculated times and temperatures of ageing (Tables 3 and 4), can be graphically presented in Figs. 5 and 6 , showing the expected ageing period and the degree of degradation as a function of the ageing temperature. If, however, we move along a curve, the same level of ageing or degradation is achieved.

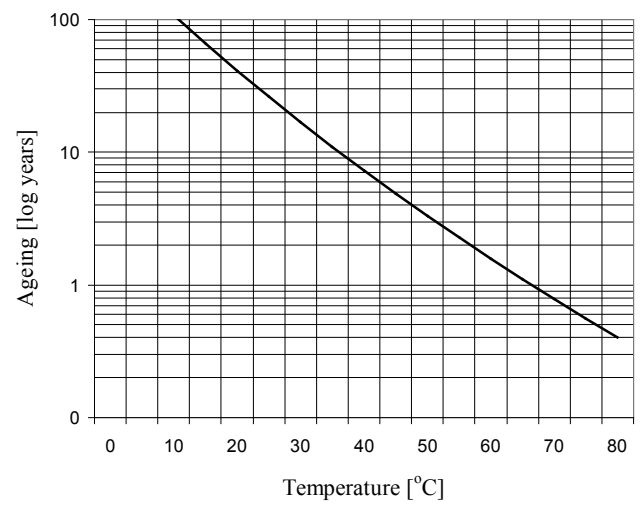

Fig. 5. Ageing of vacuum insulation panels (VIP); expected time when thermal conductivity reaches double the initial value in relation to service life temperature

Prognosis of behaviour when exposed to lower temperatures during the lifetime of the product, according to Arrhenius law, is carried out by extrapolation to longer time periods, taking into account the activation energy $E_{a}=66.35 \mathrm{~kJ} / \mathrm{mol}$ (Table 4).

Ageing in accordance with the times and temperatures listed in Tables 3 and 4, is such that complete disintegration of the product, or the end of its expected service life, does not occur except in cases of

Table 3. Extrapolation of accelerated ageing over shorter periods of time

\begin{tabular}{lcccccccc}
\hline \multicolumn{1}{c}{ Accelerated time [days] } & 240 & 120 & 90 & 60 & 30 & 21 & 14 & 7 \\
\hline $\begin{array}{l}\text { Exposure temperature of VIP panel, when its thermal } \\
\text { conductivity reached double its initial value }\left[^{\circ} \mathrm{C}\right]\end{array}$ & 72.6 & 83.3 & 88.0 & 94.7 & $106.8^{*}$ & $113.4^{*}$ & $1^{121.2^{*}}$ & $1^{135.1^{*}}$ \\
\hline
\end{tabular}

* because of irreversible damage (chemical decomposition), VIP panels should not be exposed to such high temperatures.

Table 4. Extrapolation of accelerated ageing over longer periods of time

\begin{tabular}{|c|c|c|c|c|c|c|c|c|}
\hline Expected lifetime [years] & 1 & 2 & 3 & 5 & $10^{*}$ & $15^{\star}$ & $20^{*}$ & 30 * \\
\hline $\begin{array}{l}\text { Exposure temperature of VIP panel, when its thermal } \\
\text { conductivity reached double its initial value }\left[{ }^{\circ} \mathrm{C}\right]\end{array}$ & 66.4 & 56.7 & 51.3 & 44.7 & 36.1 & 31.3 & 28.0 & 23.5 \\
\hline
\end{tabular}

* accuracy of extrapolation to such a long service life is questionable. 
extremely high temperatures, when such degradation occurs and results in non-reversible degradation or leads to chemical degradation.

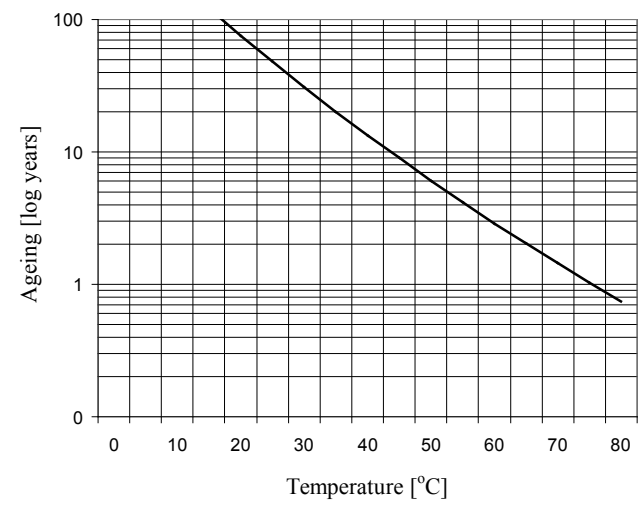

Fig. 6. Ageing of vacuum insulation panels (VIP): expected time when thermal conductivity reach value of $12 \mathrm{~mW} /(\mathrm{m} \cdot \mathrm{K})$ in relation with service life temperature

\section{CONCLUSIONS}

As a result of accelerated ageing laboratory test measurements, calculation simulation analysis and other scientific investigations, it can be concluded that VIP panels are a durable and high quality product, mainly in terms of maintaining exceptional thermal insulation, which was confirmed during testing, measurements and analysis taking into account Arrhenius law.

VIP panels can be used for insulating barriers, both in the industry (household appliances, laboratory equipment, medical devices, equipment for various manufacturing and other processes), transport and trade (refrigeration trucks, refrigeration containers, refrigerated boxes, food machines and refrigerators, mobile homes, campers and other vehicles), as well as for construction purposes (outer walls, terraces, special panels, containers, for insulation of alternative systems for cooling and ventilation [25] and in general where space is very valuable). Due to their high price, the use of VIP panels is justified in particular when there is a lack of space for thermal insulation. VIP panels provide, with minimum thicknesses, much higher thermal insulation than in standard, widely used construction insulation materials.

Caution should be exercised during transport, storage and manipulation with VIP panels. Packaging of the finished product is recommended in well protected boxes. Mechanical damage during the installation and use of VIP panels should be prevented at all costs. Exposure of VIP panels is recommended in dry, not excessive humid conditions, with thermal periodic loads up to $80{ }^{\circ} \mathrm{C}$, without the presence of mechanical damage, such as piercing, strong abrasion, bending or other deformations.

On the basis of our assumptions, service life is the time until the thermal conductivity value is double the initial value of the insulation panel. The results of our accelerated tests show that the thermal conductivity of a VIP panel exposed to constant ambient temperature $\left(25{ }^{\circ} \mathrm{C}\right.$ for indoor conditions) doubles, i.e., thermal insulation property of VIP panel falls by $50 \%$, after a period of 26.2 years and a thermal conduction value of $12 \mathrm{~mW} /(\mathrm{m} \cdot \mathrm{K})$ is reached after 48.1 years.

\section{NOMENCLATURES}

A pre-exponent factor or frequency factor of a particular reaction $[1 / \mathrm{s}]$

$E_{a} \quad$ activation energy [J/mol]

$k \quad$ specific rate of reaction, reaction constant factor or reaction speed $[1 / \mathrm{s}]$

$k_{1} \quad$ specific reaction rate under test conditions $[1 / \mathrm{s}]$

$k_{2} \quad$ specific reaction rate under normal or working conditions $[1 / \mathrm{s}]$

$R \quad$ ideal gas constant, $R=8.314472 \mathrm{~J} /(\mathrm{K} \cdot \mathrm{mol})$

$T \quad$ temperature $[\mathrm{K}]$

$T_{1} \quad$ test temperature [K]

$T_{2} \quad$ operating or working temperature $[\mathrm{K}]$

$\alpha_{T} \quad$ coefficient of acceleration of ageing due to degradation at elevated temperatures [-]

$\tau_{1} \quad$ time to degradation at an accelerated ageing test temperature [hour, day, week, month, year]

$\tau_{2} \quad$ time to degradation at operating temperature, therefore during normal use [month, year, decade].

\section{REFERENCES}

[1] Tenpierik, M.J., Cauberg, J.J.M. (2007). VIP integrated facade designs: the advantage of combining high thermal performance with limited construction thickness. Proceedings of the $24^{\text {th }}$ International - PLEA Conference on Passive and Low Energy Architecture, PLEA/NUS/RBP, p. 303-310.

[2] Glasstone, S. (1951). Textbook of Physical Chemistry. Macmillan \& Co. Ltd., London, p. 1193-1210.

[3] Carmi, Y. (2011). Developing 60 year lifetime metallized VIP laminates - Challenges and solutions. $10^{\text {th }}$ International Vacuum Insulation Symposium, Vacuum Insulation Panels: Advances in Applications, p. 167-170.

[4] Kunič, R., Orel, B., Krainer, A. (2011). An assessment of the impact of accelerated ageing on the service life of 
bituminous waterproofing sheets. Journal of Materials in Civil Engineering, vol. 23, no. 12, p. 1746-1754, DOI:10.1061/(ASCE)MT.1943-5533.0000326.

[5] Gillen, K.T., Bernstein, R., Celina, M. (2004). Non - arrhenius behavior for oxidative degradation of chlorosulfonated polyethylene materials. Polymer Degradation and Stability, vol. 87, no. 2, p. 335-346, DOI:10.1016/j.polymdegradstab.2004.09.004.

[6] Jabukowitcz, I., Nazdaneh, Y., Geart, T. (1999). Effects of accelerated and natural ageing on Plasticized Polyvinyl Chloride (PVC). Polymer Degradation and Stability, vol. 66, no. 3, p. 415-421, DOI:10.1016/ S0141-3910(99)00094-4.

[7] Kunič, R., Mihelčič, M., Orel, B., Slemenik Perše, L., Bizjak, M., Kovač, J., Brunold, S. (2011). Life expectancy prediction and application properties of novel polyurethane based thickness sensitive and thickness insensitive spectrally selective paint coatings for solar absorbers. Solar Energy Materials And Solar Cells, vol. 95, no. 11, p. 2965-2975, DOI:10.1016/j. bbr.2011.03.031.

[8] Kunič, R., Koželj, M., Orel, B., Šurca Vuk, A., Vilčnik, A., Slemenik Perše, L., Merlini, D., Brunold, S. (2009). Adhesion and thermal stability of thickness insensitive spectrally selective (TISS) polyurethanebased paint coatings on copper substrates. Solar Energy Materials And Solar Cells, vol. 93, no. 5, p. 630-640, DOI:10.1016/j.solmat.2008.12.026.

[9] Jorgensen, G. (2003). A phenomenological approach to obtaining correlations between accelerated and outdoor exposure test results of organic materials. New Directions in Coatings Performance Technology, ASTM STP 1435, ASTM International, p. 12-22.

[10] Chitambira, B., AL-Tabbaa, A., Perera, A.S.R., Yu, X.D. (2007). The activation energy of stabilized/ solidified contami-nated soils. Journal of Hazardous Materials, vol. 141, no. 2, p. 422-429, DOI:10.1016/j. jhazmat.2006.05.080.

[11] Jorgensen, G., Brunold, S., Carlsson, B., Möller, K., Heck, M., Köhl, M. (2003). Durability of polymeric glazing materials for solar applications. First European Wethering Symposyum, p. 1-15.

[12] Köhl, M., Carlsson, B., Jorgensen, G., Czanderna, A.W. (2004). Performance and durability assessment: Optical Materials for Solar Thermal Systems, Elsevier, Oxford.

[13] Liaw, B.Y., Roth, E.P., Jungst, R.G., Nagasubramanian, G., Case, H.L., Doughy, D.H. (2003). Correlation of Arrhenius behaviours in power and capacity fades with cell impedance and heat generation in cylindrical lithium-ion cells. Journal of Power Sources, vol. 119121, p. 874-886, DOI:10.1016/S0378-7753(03)001964.

[14] Celina, M., Gillen, K.T., Assink, R.A. (2005). Accelerated ageing and lifetime prediction: Review of non-Arrhenius behaviour due to two competing processes. Polymer Degradation and
Stability, vol. 90, no. 3, p. 395-404, DOI:10.1016/j. polymdegradstab.2005.05.004.

[15] Sonibare, O.O., Egashira, R., Adedosu, T.A. (2003). Thermo-oxidative reactions of Nigerian oil sand bitumen. Thermochimica Acta, vol. 405, no. 2, p. 195 205, DOI:10.1016/S0040-6031(03)00192-8.

[16] Nohara, M. (1997). Study of prediction method for thermo-oxidative life of plastics by thermal analysis. JSAE Review, vol. 19, no. 3, p. 263-268, DOI:10.1016/ S0389-4304(98)00009-5.

[17] Owens, J.W. (1997). Life cycle assessment: constraints on moving from inventory to impact assessment. Journal of Industrial Ecology, vol. 1, no. 1, p. 37-49, DOI:10.1162/jiec.1997.1.1.37.

[18] Bochen, J., Gil, S., Szwabowski, J. (2005). Influence of ageing process on porosity changes of the external plasters. Cement and concrete composites, vol. 27, no. 7-8, p. 769-775, DOI:10.1016/j. cemconcomp.2005.01.003.

[19] Budrugeac, P. (2001). Thermal degradation of glass reinforcement epoxy resin and polychloroprene rubber: the correlation of kinetic parameters of isothermal accelerater ageing with those obtained from nonisothermal data. Polymer Degradation and Stability, vol. 74, no. 1, p. 125-132, DOI:10.1016/S01413910(01)00112-4.

[20] Gillen, K.T., Bernstein, R., Derzon, D.K. (2004). Evidence of non-Arrhenius behaviour from laboratory ageing and 24-year field ageing of polychloroprene rubber materials. Polymer Degradation and Stability, vol. 87, no. 1, p. 57-67, DOI:10.1016/j. polymdegradstab.2004.06.010.

[21] Fawcett, A.H., Mcnally, T. (1999). Blends of bitumen with various polyolefins. Polymer, vol. 40, no. 23, p. 6337-6349, DOI:10.1016/S0032-3861(98)00779-4.

[22] Czarderna, A.W., Pern, F.J. (1995). Encapsulation of PV modules using ethylene vinyl acetate (EVA) copolimer as a pottant: A critic review. Solar Energy Materials and Solar Cells, vol. 43, no. 2, p. 101-181, DOI:10.1016/0927-0248(95)00150-6.

[23] Brunold, S., Frei, U., Carlsson, B., Möller, K., Köhl, M. (2000). Accelerated life testing of solar absorber coatings: Testing procedure and results. Solar Energy, vol. 68, no. 4, p. 313-323, DOI:10.1016/S0038092X(00)00034-7.

[24] Mukhopadhyaya, P., Kumaran, M.K., Sherrer, G., van Reenen, D. (2011). An investigation on longterm thermal performance of vacuum insulation panels (VIPs). 10 th $^{\text {th }}$ International Vacuum Insulation Symposium, Vacuum Insulation Panels: Advances in Applications, p. 143-148.

[25] Stritih, U., Butala, V. (2011). Energy savings in building with a PCM free cooling system. Strojniški vestnik - Journal of Mechanical Engineering, vol. 57, no. 2, p. 125-134, DOI:10.5545/sv-jme.2010.066. 